\title{
SODIUM HYDRIDE PRECIPITATION IN SODIUM COLD TRAPS
}

\author{
by
}

C. C. McPheeters and D. J. Raue

ARGONNE NATIONAL LABORATORY, ARGONNE, ILLINOIS

Prepared for the U. S. DEPARTMENT OF ENERGY

under Contract W-31-109-Eng-38 


\section{DISCLAIMER}

This report was prepared as an account of work sponsored by an agency of the United States Government. Neither the United States Government nor any agency Thereof, nor any of their employees, makes any warranty, express or implied, or assumes any legal liability or responsibility for the accuracy, completeness, or usefulness of any information, apparatus, product, or process disclosed, or represents that its use would not infringe privately owned rights. Reference herein to any specific commercial product, process, or service by trade name, trademark, manufacturer, or otherwise does not necessarily constitute or imply its endorsement, recommendation, or favoring by the United States Government or any agency thereof. The views and opinions of authors expressed herein do not necessarily state or reflect those of the United States Government or any agency thereof. 


\section{DISCLAIMER}

Portions of this document may be illegible in electronic image products. Images are produced from the best available original document. 
The facilities of Argonne National Laboratory are owned by the United States Government. Under the terms of a contract (W-31-109-Eng-38) among the U.S. Department of Energy, Argonne Universities Association and The University of Chicago, the University employs the staff and operates the Laboratory in accordance with policies and programs formulated, approved and reviewed by the Association.

\section{MEMBERS OF ARGONNE UNIVERSITIES ASSOCIATION}

The University of Arizona

Carnegie-Mellon University

Case Western Reserve University

The University of Chicago

University of Cincinnati

Illinois Institute of Technology

University of Illinois

Indiana University

The University of Iowa

Iowa State University
The University of Kansas

Kansas State University

Loyola University of Chicago

Marquette University

The University of Michigan

Michigan State University

University of Minnesota

University of Missouri

Northwestern University

University of Notre Dame
The Ohio State University

Ohio University

The Pennsylvania State University

Purdue University

Saint Louis University

Southern Illinois University

The University of Texas at Austin

Washington University

Wayne State University

The University of Wisconsin-Madison

\section{NOTICE}

This report was prepared as an account of work sponsored by an agency of the United States Government. Neither the United States Government or any agency thereof, nor any of their employees, make any warranty, express or implied, or assume any legal liability or responsibility for the accuracy, completeness, or usefulness of any information, apparatus, product, or process disclosed, or represent that its use would not infringe privately owned rights. Reference herein to any specific commercial product, process, or service by trade name, mark, manufacturer, or otherwise, does not necessarily constitute or imply its endorsement, recommendation, or favoring by the United States Government or any agency thereof. The views and opinions of authors expressed herein do not necessarily state or reflect those of the United States Government or any agency thereof.

Printed in the United States of America

Available from

National Technical Information Service

U. S. Department of Commerce

5285 Port Royal Road

Springfield, VA 22161

NTIS price codes

Printed copy: $\mathrm{A} 03$

Microfiche copy: A01 
ANL-79-101

\begin{abstract}
ARGONNE NATIONAL LABORATORY
9700 South Cass Avenue

Argonne, Illinois 60439
\end{abstract}

SODIUM HYDRIDE PRECIPITATION IN SODIUM COLD TRAPS

by

C. C. McPheeters and D: J. Raue

Chemical Engineering Division

June 1980

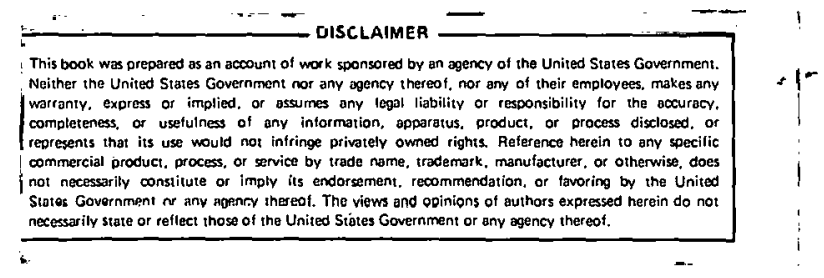


3

THIS PAGE

\section{WAS INTENTIONALLY \\ LEFT BLANK}


TABLE OF CONTENTS

$\underline{\text { Page }}$

ABSTRACT

I. INTRODUCTION

II. DESCRIPTION OF THE COLD-TRAP MODEL . . . . . . . . . . . 2

III. TEST APPARATUS .......................... 4

IV. EXPERIMENTAL RESULTS . . . . . . . . . . . . . . 8

A. Hydrogen Injector Performance Tests . . . . . . . 8

B. O-H Analyzer Tests . . . . . . . . . . . . . . 8

C. ACT Tests and ACTMODEL Simulations ........... 10

V. CONCLUSIONS AND FUTURE WORK . . . . . . . . . . . . 16

REFERENCES . . . . . . . . . . . . . . . . . . . 17

iii 


\section{LIST OF FIGURES}

No.

1. ACTMODEL Logic Flow Diagram . . . . . . . . . . . . .

2. AMPS System Flow Diagram . . . . . . . . . . . . . . . .

3. Flow Diagram of Experimental Cold Trap Section . . . . . . . .

4. Analytical Cold Trap . . . . . . . . . . . . . . . . 7

5. Oxygen-Hydrogen Analytical Device . . . . . . . . . . . 7

6. Hydrogen Concentration at the Injector Inlet and Outlet During a Hydrogen Injection . . . . . . . . . . . . . . . . 9

7. Effect of Quantity of NaH Deposited in the ACT on the MassTransfer Coefficient . . . . . . . . . . . . . . . . . .

8. Effect of NaH Deposition on the Surface Area Available for Precipitation . . . . . . . . . . . . . . . . . .

9. Contact Print of Post Test Neutron Radiograph of Packless ACT Number 7 . . . . . . . . . . . . . . . . . . . .

10. Hydrogen Distribution in ACT Number 7 as Determined by OHA Analyses . . . . . . . . . . . . . . . . . . . .

11. Hydrogen Distribution in ACT Number 4 as Determined by OHA Analyses

\section{LIST OF TABLES}

No.

$\underline{T, i, t e}$

1. Standard Samples Run with the $0-\mathrm{H}$ Analyzer . . . . . . . . . . .

2: Summary of Results of Model Calculations . . . . . . . . . . 


\title{
SODIUM HYDRIDE PRECIPITATION IN SODIUM COLD TRAPS
}

by

\author{
C. C. McPheeters and D. J. Raue
}

\begin{abstract}
A series of experiments have been performed to test a calculational model for precipitation of $\mathrm{NaH}$ in sodium cold traps. The calculational model, called ACTMODEL, is a computer simulation that uses the system geometry and operating conditions as input to calculate a mass-transfer coefficient and the distribution of $\mathrm{NaH}$ in a cold trap.
\end{abstract}

The ACTMODEL was tested using an analytical cold trap (ACT) that is simple and essentially one-dimensional. The ACT flow and temperature profile can be controlled at any desired condition. The ACT was analyzed destructively after each test to measure the actual $\mathrm{NaH}$ distribution.

Excellent agreement was obtained between the ACTMODEL simulations and the experiments. Mass-transfer coefficients ranging upward from $6 \times 10^{-5} \mathrm{~m} / \mathrm{s}$ were measured in both packless and packed traps. As much as a fourfold increase in precipitation surface area was observed with increasing amount of $\mathrm{NaH}$ deposited.

\section{INTRODUCTION}

Cold traps have been used extensively to control impurity concentrations in liquid-sodium systems because of their simplicity, economy of operation, and effectiveness. The cold-trapping method operates on the principle of lowering the solubility of the impurity in sodium by lowering the sodium temperature, thus causing precipitation in a controlled, low-temperature region of the system. This method has performed quite satisfactorily on a variety of sodium systems for many years; however, in recent years, a problem was discovered that could greatly reduce the attractiveness of the cold-trapping method for reactor sodium systems. This problem arises from water-side corrosion of the steam-generator tubes which releases hydrogen that diffuses through the tubes.into the sodium system. Measurements of this corrosion rate and the resulting hydrogen source term with both experimental systems ${ }^{l}$ and full-scale reactor systems ${ }^{2}$ have shown that the hydrogen source is so large that the capacity of the cold trap to retain the sodium hydride may be exceeded within one year of ful1-power reactor operation. Estimates of this one-year lifetime are based on the assumption that the trap is plugged when ten percent of the mesh volume is filled with sodium hydride. This assumption is borne out by past experience with cold traps which has shown that, under normal conditions, the mesh tends to plug when a ten-volume percent loading is achieved. ${ }^{3}, 4$ However, occasionally, a cold trap has been made to retain a loading of twenty to thirty percent before plugging occurs. 5 If a trap could be designed and operated in such a way as to accommodate a fifty-percent loading, the lifetime could be extended to about five years, which would be acceptable for reactor operation. 
The primary cause for premature plugging of the cold trap appears to be localized precipitation that builds a blockage across the flow path before the rest of the mesh volume has been utilized. Cases have been observed in which heavy precipitation occurred in the first ten to twenty percent of the mesh while the remaining mesh remained absolutely clean. ${ }^{6}$ The purpose of this work is to develop design features and operating procedures to increase the utilization of the cold trap and, thus, increase the loading as much as possible. The approach we have chosen for achieving this goal is to develop a computer model that accurately calculates the distribution of sodium hydride deposits in a cold trap under any given conditions of flow, temperature, and mesh design. These design and operating procedures can then be studied to determine the optimum design and operating procedures for maximum cold-trap loading.

\section{DESCRIPTION OF THE COLD-TRAP MODEL}

The first version of the computer model (ACTMODEL) for precipitation of sodium bydride in a cold trap was developed specifically for a simple Analytical Cold Trap (ACT), which is a mesh-filled tube having a well-defined temperature gradient and sodium flow. The model considers the ACT as being one-dimensional, $i . e .$, no radial flow or temperature gradient is considered. As the model now exists, certain assumptions are implicit in the methods it uses in calculating sodium hydride mass distributions. Although some of these assumptions were known to be invalid, they were incorporated in the first version for simplicity. Some of these implicit, but debatable assumptions are: 1) $\mathrm{NaH}$ nucleation occurs readily on solid surfaces with no significant threshold supersaturation. As discussed below, the experimental evidence supports this assumption; however, large supersaturations can exist in the liquid phase when no solid surfaces are available for nucleation. 2) The surface area for mass deposition remains constant and equal to the stainless steel surface area even after deposition of significant quantities of $\mathrm{NaH}$. As discussed below, this assumption is clearly incorrect; however, the ACTMODEL was very useful in measuring changes in this surface area. 3) The rate of $\mathrm{NaH}$ deposition is liquid-phase diffusion controlled and is described by ${ }^{7-10}$

$$
\frac{d m}{d t}=k A(C-C e)^{n}
$$

where $\dot{\mathrm{m}}=$ mass of hydrogen in the deposit, $\mathrm{kg}$

$\mathrm{t}=\mathrm{time}, \mathrm{s}$

$\mathrm{k}=$ mass-tiransfer coefficient, $\mathrm{m} / \mathrm{s}$

$A=$ deposition surface area, $\mathrm{m}^{2}$

$\dot{C}=$ local hydrogen concentration in sodium, $\mathrm{kg} / \mathrm{m}^{3}$

$\mathrm{Ce}=$ saturation hydrogen concentration in sodium based on the local temperature, $\mathrm{kg} / \mathrm{m}^{3}$

$\mathrm{n}=$ exponent indicating the order of the process, assumed to be unity. 
The logic flow used by ACTMODEL is shown schematically in Fig. 1 . The required input includes the configuration data such as ACT length, diameter, and mesh density; temperature profile data; and the sodium conditions of flow rate and hydrogen inlet and outlet concentrations. The configuration data are used to calculate surface area per unit length, and the sodium velocity and the temperature profile are used to calculate the saturation concentration profile along the length of the ACT. This saturation concentration is given by the relationship of Vissers et al. 11 .

$$
\log C_{e}(p p m)=6.067-\frac{2880}{T(K)}
$$

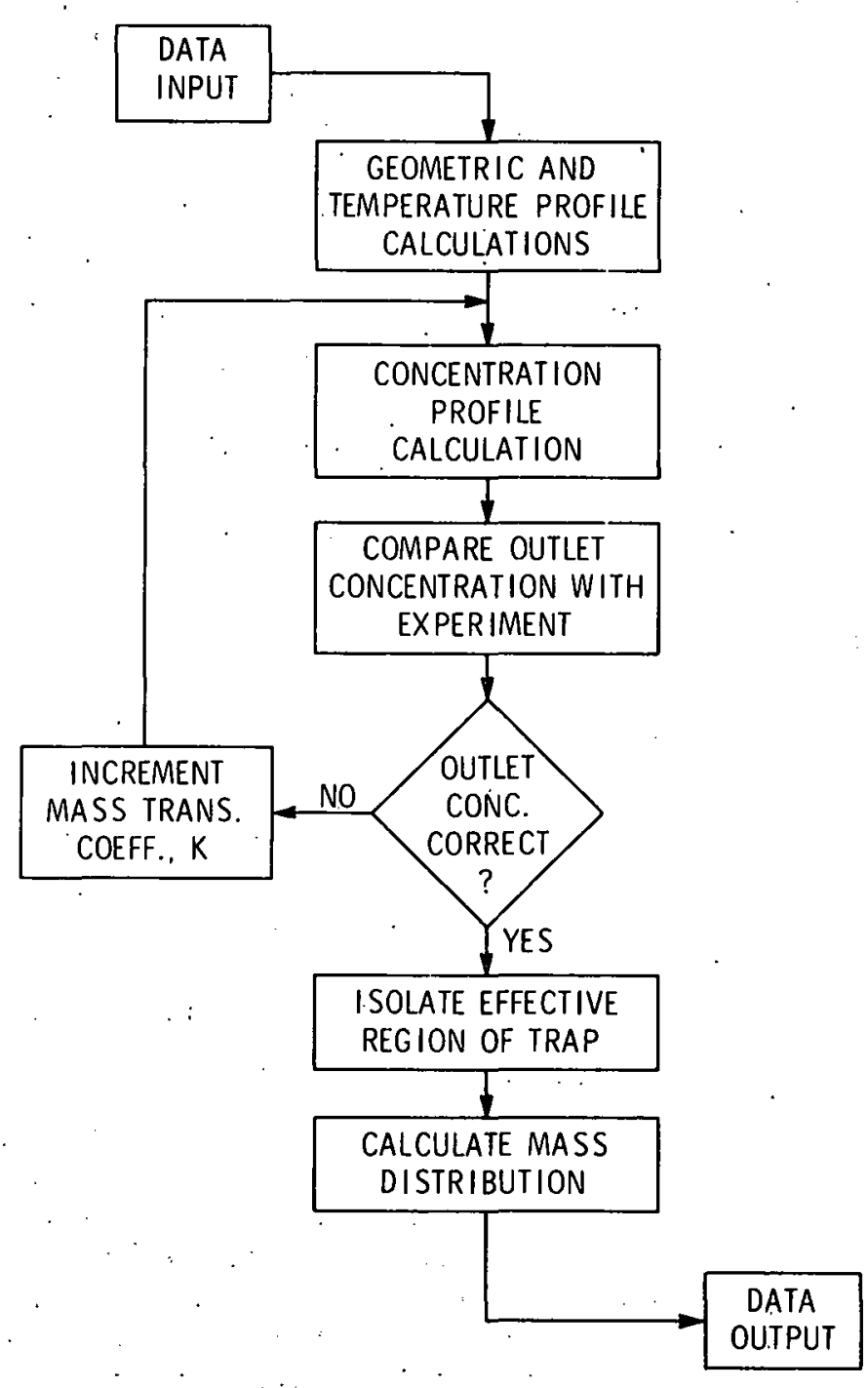

Fig. 1. ACTMODEL Logic Flow Diagram 
The next step in the calculation is to determine the mass-transfer coefficient, $k$, that will duplicate the observed cold-trap outlet hydrogen concentration, given the experimental conditions of inlet concentration, temperature profile, sodium flow rate, etc. Equations 1 and 2 are used in. conjunction with appropriate mass-balance relationships to calculate the hydrogen 'concentration in sodium along the length of the ACT. When Eqs. $i$ and 2 are combined, the resulting differential equation is extremely difficult to solve by analytical means. Therefore, the equation is solved numerically by the Runge-Kutta method ${ }^{12}$ using a differential increment of 0.01 times the ACT length. The mass-transfer coefficient is incremented between trial calculations until the calculated outlet hydrogen concentration matches the experimentally observed outlet concentration.

After the concentration profile is established, the portion of the ACT that is effectively removing hydrogen from the sodium stream, i.e., the section of the ACT in which the saturation hydrogen concentration is lower than the inlet hydrogen concentration, is identified. This effective length is divided into 100 increments and the quantity of hydrogen that accumulates in each increment is calculated for the length of time of the cold-trapping experiment.

The ACTMODEL has the capability of calculating several segments of one experiment in series, so that, if an experiment parameter such as the temperature profile or inlet hydrogen concentration, for example, is changed in the course of an experiment, the same parameters may be changed at the same time interval for the ACTMODEL simulation. Hydrogen mass deposited in early segments of the simulation is not disturbed by subsequent ACTMODEL time segments.

The output of ACTMODEL includes key configuration data such as mesh packing density, ACT dimensions, sodium velocity, temperature and hydrogenconcentration profiles, hydrogen-mass-deposit distribution, and the calculated mass-transfer coefficient. This information is printed out at the end of each time segment of a given experiment simulation.

\section{TEST APPARATUS}

Sodium hydride precipitation experiments were performed during 1978 and 1979 at Argonne National Laboratory using the Apparatus for Monitoring and Purifying Sodium (AMPS). The AMPS is a forced-circulation sodium system that contains $320 \mathrm{~kg}$ ( $\sim 100 \mathrm{gal}$ ) and is shown in Fig. 2. The sodium is circulated in two legs of the AMPS: the purification leg contains a cold trap and a getter trap (titanium sponge) for removing hydrogen and oxygen from the system, and the experimental leg provides for rapid recirculation of sodium, multiple analyses of hydrogen and oxygen, and testing of various cold traps and configurations. The sodium in the main vessel is recirculated at a constant rate of approximately $1.1 \mathrm{~kg} / \mathrm{s}$ to assure adequate mixing. A small stream is taken from this main recirculation stream at a typical flow of $10 \mathrm{~g} / \mathrm{s}$ for use in the experimental cold-trap section of AMPS. 


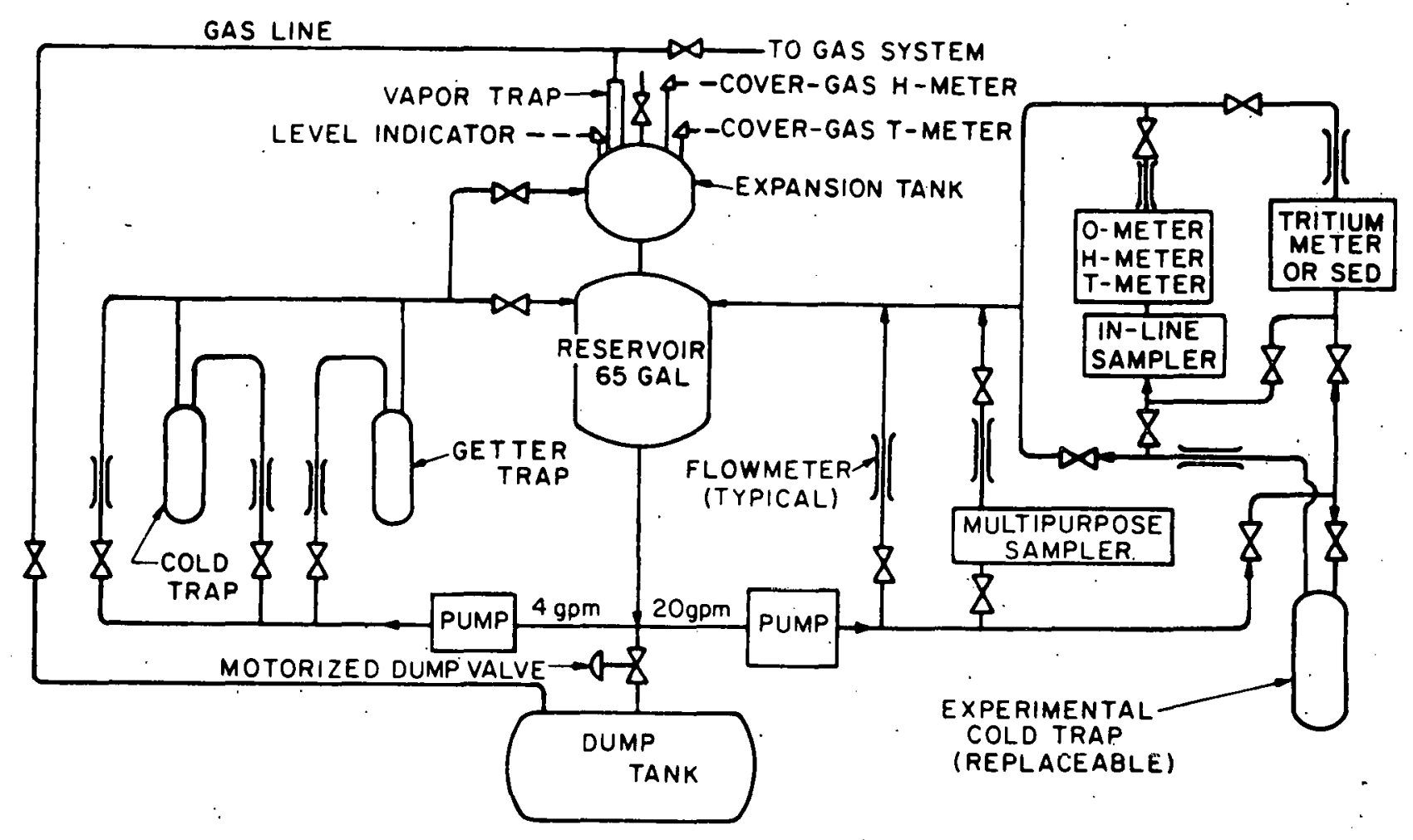

Fig. 2. AMPS System Flow Diagram

The experimental cold-trap section of AMPS is shown schematically in Fig. 3. The small sodium stream is split into two segments: the first flows to hydrogen meter number 1 where the hydrogen concentration is measured continuously, and the second segment enters the hydrogen injection device. 'The hydrogen meters.used in these experiments are the nickel membrane diffusion type developed by Vissers et al. 11 They are normally operated in the so-called dynamic mode where the ion-pump current is proportional to the hydrogen concentration. The meters are operated in the equilibrium mode on a daily basis to provide continual meter calibration and cross-checking between meters. During ACT experiments, the hydrogen meters are operated in the dynamic mode continuously and $i t$, is not possible to check one meter against the other.

The hydrogen injector is essentially a hydrogen meter operated in reverse.

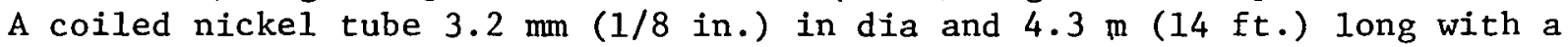
$0.38-\mathrm{mm}$ ( $0.015 \mathrm{in.)}$ wall thickness is placed in flowing sodium in a $750 \mathrm{~K}$ temperature zone." Pure hydrogen gas enters the nickel tube and flows through the tube wall by diffusion. The hydrogen flow is measured with a mass flowmeter, and typical injection rates of 6.7 to $27 \mathrm{~mm}^{3} / \mathrm{s}$ have been used in these experiments. The hydrogen concentration in the sodium entering the ACT is inferred from that measured with hydrogen meter number 1 plus the quantity of hydrogen added at the injector. Some preliminary experiments were done to confirm the accuracy of this inferred hydrogen concentration, and they are discussed in following sections.

Sodium flowing from the hydrogen injector flows through a heat exchanger where it is cooled prior to entering the ACT. Flow continues through the ACT; back through the heat exchanger, and to hydrogen meter number 2 where the outlet hydrogen concentration is:measured. Sodium from both hydrogen meters is returned to the main sodium recirculation stream. 


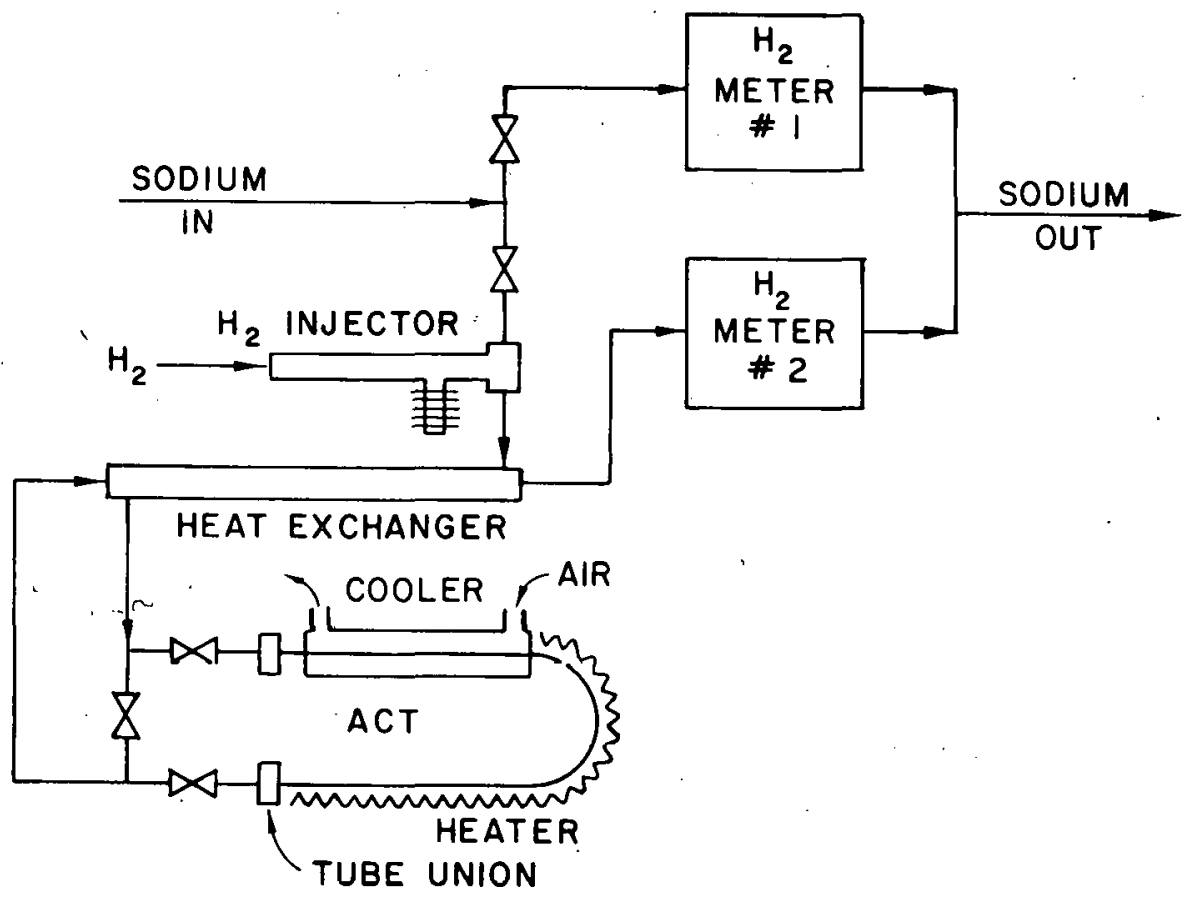

Fig. 3. Flow Diagram of Experimental Cold Trap Section

The Analytical Cold Trap is shown schematically in Fig. 4. Sodium enters the packed section which is $0.56 \mathrm{~m}$ long with a $17.5-\mathrm{mm}$. inside dia outer tube and a $9.5-\mathrm{mm}$ dia thermocouple well on the centerline. The packing is arranged in $50-\mathrm{mm}$ segments for ease of posttest disassembly. A controlled air stream is used to cool the sodium stream in the mesh region. A proportional-band temperature controller is used to control a variable-speed blower motor supplying the cooling air. This method of temperature control has been found to produce very stable temperatures over long time periods. Sodium leaving the mesh region is heated as rapidly as possible to prevent precipitation of hydrogen beyond the mesh.

After the ACT test is completed, the sodium flow is stopped and the sodium is frozen in place in the ACT. The Conoseal unions are then disconnected and the ACT is transferred to a helium-filled glove box for cutting into. segments. The 50-mm segments are stored individually in sealed sample jars to prevent any reaction with impurities that might enter the glove box.

Each ACT segment is analyzed for total hydrogen content by means of the $0-\mathrm{H}$ analytical device shown in Fig. 5. In the glove box, the segment is placed in a nickel sample boat which, in turn, is placed in the $0-H$ analyzer (OHA). The OHA is sealed and evacuated, and the copper tube is pinched closed to isolate the sample in vacuum. The OHA is placed in a furnace and heated to $670 \mathrm{~K}$ while ultra-pure helium is passed through the nicke1-tube coil. Gas leaving the OHA flows through an $870-\mathrm{K}$ CuO bed, where entrained hydrogen is converted to water. The water is then collected on a drying tube and periodically weighed until no further weight gain is noted. Tests of this analytical method have been done using standard samples of $\mathrm{NaH}$ and $\mathrm{NaOH}$ in sodium. Excellent agreement between hydrogen added and hydrogen recovered has been observed, as is discussed in the following sections. After the hydrogen 


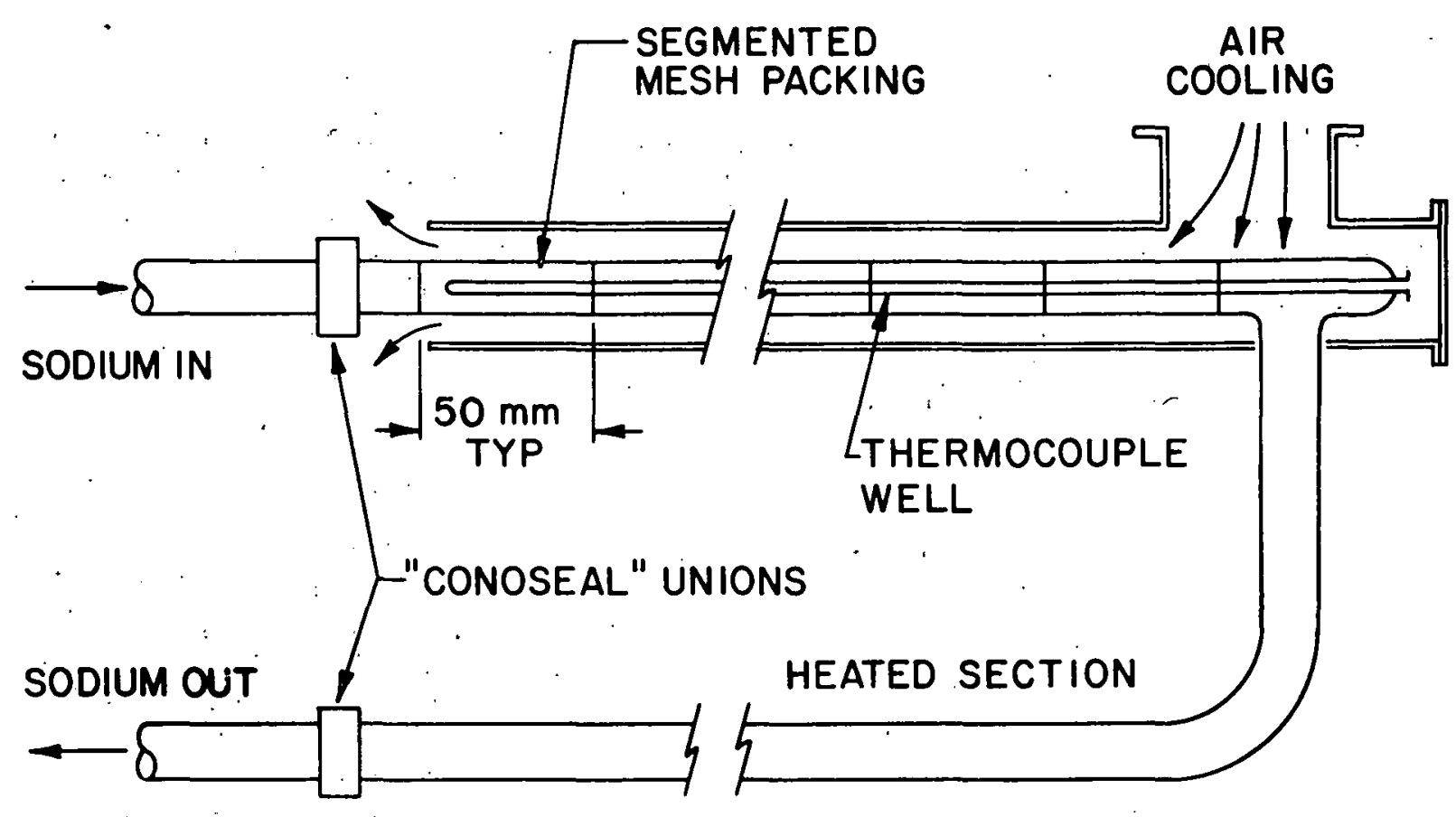

Fig. 4. Analytical Cold Trap

evaluation is completed, the sodium may be separated from the segment by simply cooling the copper tube to condense the sodium vapor. The residue left in the segment may be analyzed for total sodium to obtain an indication of the $\mathrm{Na}_{2} \mathrm{O}$ content of the segment. Of course, other stable, nonvolatile sodium compounds would be interpreted as $\mathrm{Na}_{2} \mathrm{O}$ by this method.

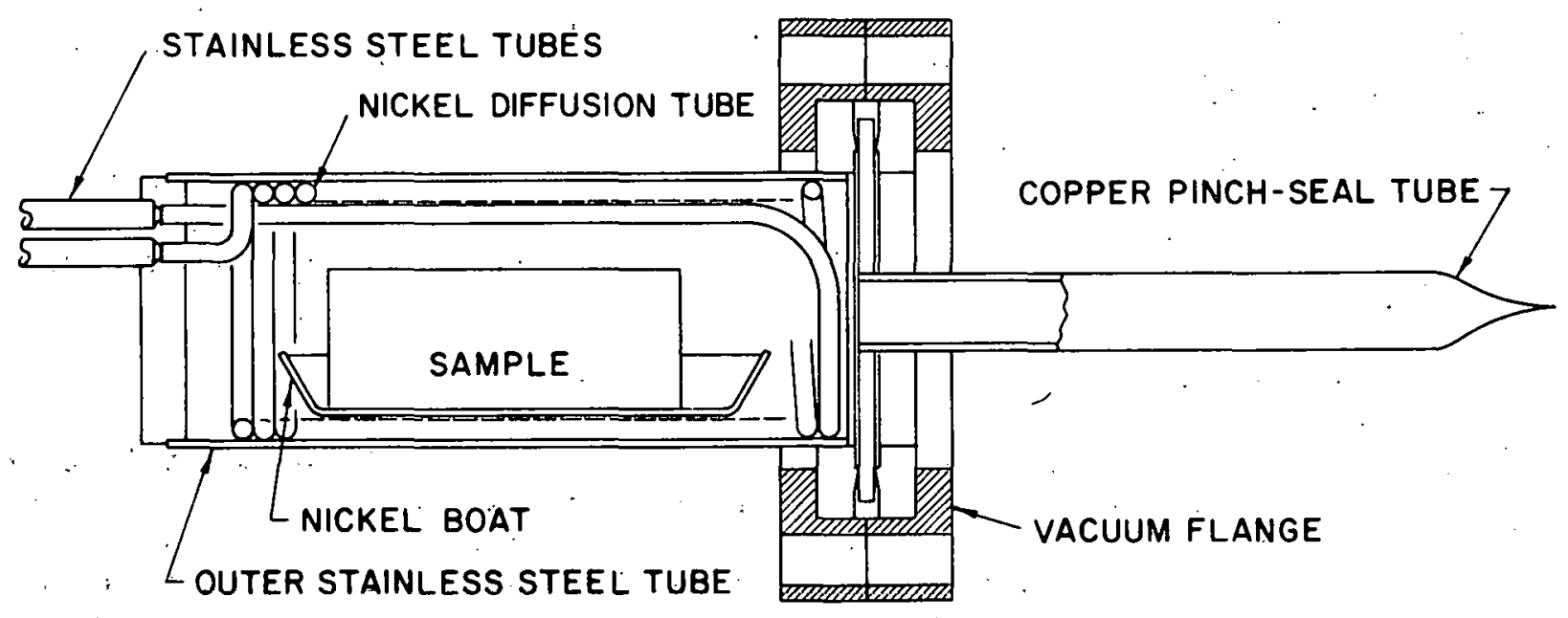

Fig. 5. Oxygen-Hydrogen Analytical Device 


\section{EXPERIMENTAL RESULTS}

The results of two preliminary tests are critical to the interpretation of the ACT experimental results; the two tests are 1) checking the hydrogen injector to determine whether the amount of hydrogen measured by the mass flowmeter corresponded to the hydrogen concentration increase observed with the hydrogen meters, and 2) testing the OHA technique using both $\mathrm{NaH}$ and $\mathrm{NaOH}$ in sodium to determine the percentage of hydrogen recovered.

\section{A. Hydrogen Injector Performance Tests}

Previous experience with hydrogen meters and hydrogen-injection devices has shown that a reasonably long time (a few hours or more) is required to "condition" a new nickel membrane for quantitative diffusion of hydrogen into or out of sodium. For this reason, the problem of inferring the ACT inlet hydrogen concentration from the system concentration plus a known injection rate was troublesome. (The system configuration has subsequently been changed to eliminate this problem; however, these data were obtained prior to the change.)

Several tests were run to determine the accuracy of the hydrogen injections. For these tests, the ACT was bypassed and hydrogen meters 1 and 2 were monitored while hydrogen was injected at a constant, controlled rate for approximately six hours. The theoretical hydrogen-injector outlet concentration was obtained by adding the quotient, hydrogen-injection-rate/sodiumflowrate; to the inlet concentration. The results of one of these tests are shown in Fig. 6 where inlet and outlet concentrations are plotted vs. time. Since the AMPS sodium inventory is so large $(320 \mathrm{~kg})$, the inlet concentration changed very 1ittle during the injection. It can be seen that the injector tube required purging to bring the injection rate up to the theoretical level. This necessity for purging is probably due to outgassing of the nickel or reduction of compounds on the surface (such as oxides). In this test, four hours were required to bring the injection rate to near theoretical. Subsequent run times could be shortened by increased purging early in the injection period. The start of subsequent ACT runs was delayed until theoretical injection rates were achieved so that the desired inlet concentrations could be achieved.

The agreement between hydrogen meters 1 and 2 can be observed at the beginning and the end of the injection test shown in Fig. 6 . This degree of agreement between hydrogen meters was typical of that observed throughout this sequence of ACT tests.

\section{B. O-H Analyzer Tests}

The OHA was developed specifically for analyzing the ACT segments in this program. As with any new analytical technique, it was necessary to proof-test the method using samples of known composition. A series of nine tests were run in which the OHA nickel boat was loaded with weighed quantities of $\mathrm{NaH}$ or $\mathrm{NaOH}$ and sodium. These samples, containing various amounts of hydrogen, were mostly run for about $86 \mathrm{ks}(24 \mathrm{~h})$. The composition of each sample, the amount of hydrogen recovered, and the duration of each run are shown in . Table 1. All of these samples were run at $670 \mathrm{~K}$ with the apparatus and operating procedures described above. 


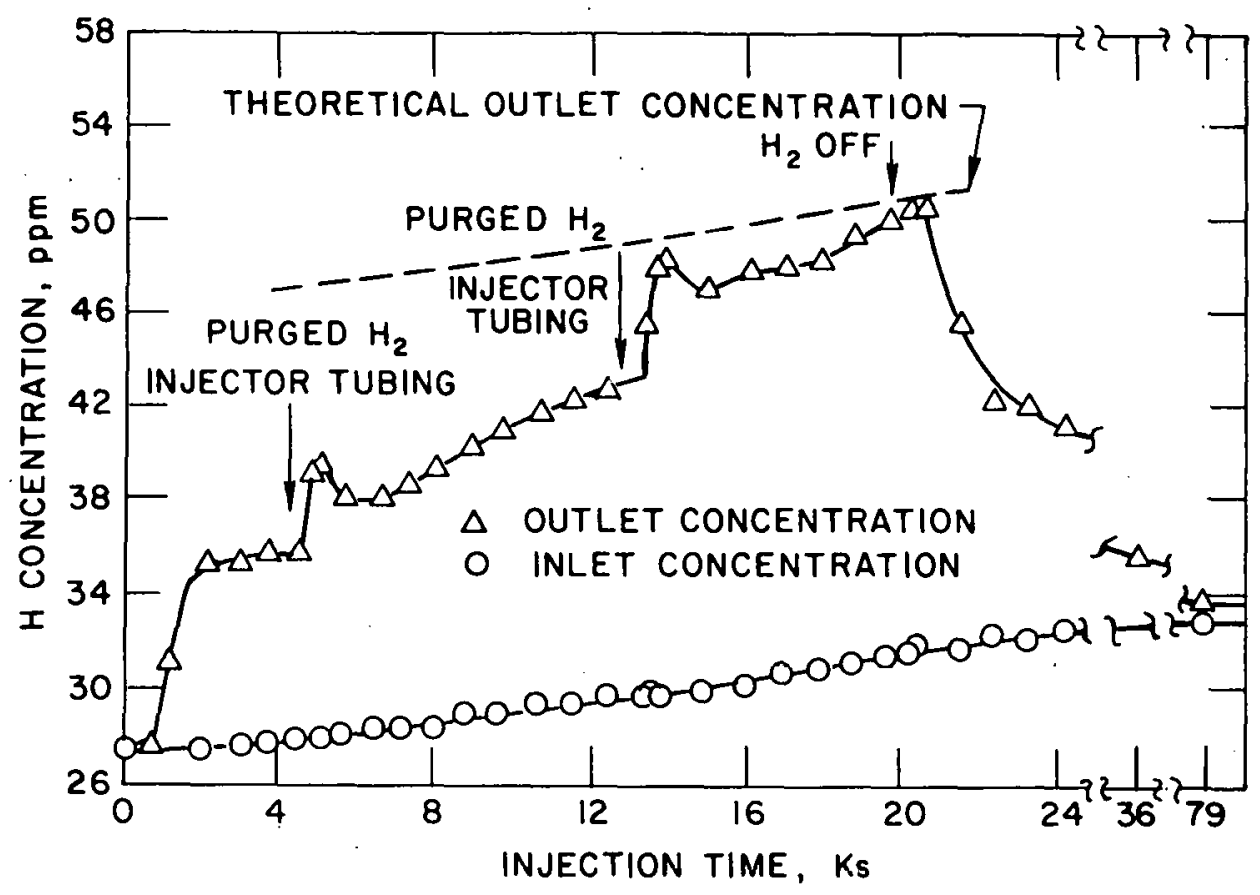

Fig. 6. Hydrogen Concentration at the Injector Inlet and Outlet During a Hydrogen Injection

Table 1. Standard Samples Run with the O-H Analyzer

\begin{tabular}{llrrrr}
\hline & & & & \multicolumn{2}{l}{$\mathrm{H}_{2}$ Recovered, } \\
\cline { 5 - 6 } No. & Composition & $\begin{array}{c}\mathrm{H}_{2} \text { Content, } \\
\mathrm{mg}\end{array}$ & $\mathrm{mg}$ & $\%$ & $\begin{array}{c}\text { Process } \\
\text { time, } \\
\mathrm{ks}\end{array}$ \\
\hline 1 & $\mathrm{NaH}$ & 11.02 & 9.55 & 86.6 & 94 \\
2 & $\mathrm{NaH}$ & 13.41 & 8.54 & 63.6 & 86 \\
3 & $\mathrm{NaOH}$ & 8.02 & 7.64 & 95.2 & 86 \\
4 & $\mathrm{NaOH}$ & 3.44 & 3.40 & 98.7 & 86 \\
5 & $\mathrm{NaOH}$ & 5.50 & 5.11 & 93.0 & 104 \\
6 & $\mathrm{NaOH}$ & 4.80 & 4.56 & 95.0 & 86 \\
7 & $\mathrm{NaH}$ & 3.94 & 3.62 & 91.7 & 86 \\
$8 \mathrm{a}$ & $\mathrm{NaH}$ & 19.92 & 12.33 & 61.9 & 86 \\
$8 \mathrm{~b}$ & $\mathrm{NaH}$ & (same as $8 \mathrm{a})$ & 18.85 & 94.6 & $173^{\mathrm{a}}$ \\
\hline
\end{tabular}

${ }^{a}$ Cummulative time for tests $8 a$ and $8 b$.

With a few exceptions, hydrogen recovery of 90 to 99 percent was observed in these tests. The exceptions (samples 1, 2, and $8 \mathrm{a}$ ) were found to be processed for too little time. The rate of diffusion of hydrogen from the low-pressure hydrogen source inside the OHA into the helium sweep gas is 1ow; therefore, in cases where more than $\sim 6 \mathrm{mg}$ of hydrogen was in the sample, processing times of $170 \mathrm{ks}$ or more were required to assure recovery of $>95 \%$ of the hydrogen. The long processing time required by this method caused the loss of some valuablc data early in the program, prior to tests $8 \mathrm{a}$ and $8 \mathrm{~b}$ which clearly demonstrated the importance of allowing sufficient processing 
time. Calculations indicated that as much as $150 \mathrm{mg}$ of hydrogen should be transferred in $86 \mathrm{ks}$ under the OHA operating conditions; however, the presence of impurity gases or coatings may greatly inhibit diffusion of hydrogen through the nickel tube. Calculations also indicated that approximately 2 to $5 \%$ of the hydrogen would be lost by diffusion through the stainless steel vessel wall. This fractional loss is low, primarily because of the diffusioninhibiting oxide coating on the outer surface of the stainless steel which should reduce the diffusion coefficient by a factor of 150 to 200.13

In samples 3 through 6 , the sodium was removed by cooling the copper tube after the hydrogen had been recovered. The residue was then analyzed for sodium (presumably present as $\mathrm{Na}_{2} \mathrm{O}$ ). Excellent agreement between these analyses and the expected amount of $\mathrm{Na}_{2} \mathrm{O}$ was achieved in all cases.

\section{ACT Tests and ACTMODEL Simulations}

A total of seven ACT tests were completed in the study of sodium hydride precipitation in cold traps. The first two tests were to test the equipment and to develop procedures for performing the tests and the post-test analyses. The remaining five tests were performed under various experimental conditions of sodium velocity, mesh packing density, and sodium hydride loading. The experimental conditions and results are summarized in Table 2. -ACT numbers 5,6 , and 7 were divided into three and four time segments, as shown in Table 2, because the experimental conditions, i.e., the temperature profile or inlet hydrogen concentration, changed slightly during the experiment. The different segments of these ACT runs can be viewed as separate experiments; however, the ACTMODEL is capable of following the changes in experimental conditions while calculating the hydrogen mass distribution in the ACT.

Two sodium velocities: 0.019 and $0.038 \mathrm{~m} / \mathrm{s}$; and three mesh packing density ranges: no packing, $220 \mathrm{~kg} / \mathrm{m}^{3}$ and 430 to $470 \mathrm{~kg} / \mathrm{m}^{3}$ were tested. Hydrogen distributions ranging from $\sim 50 \mathrm{mg} / \mathrm{m}^{2}$ to $\sim 1200 \mathrm{mg} / \mathrm{m}^{2}$ were tested, and although it is not important to this study, trapping efficiencies ranging from $210 \%$ for the packless trap to $280 \%$ for the packed traps were achieved.

The mass-transfer coefficients presented in Table 2 were calculated by the ACTMODEL code as described above. All the mass-transfer coefficients fall within the range of $1.65 \times 10^{-5}$ to $26.1 \times 10^{-5} \mathrm{~m} / \mathrm{s}$. Attempts to correlate these mass-transfer coefficients with sodium velocity or some expression for the degree of turbulence, such as the Reynolds number, were unfruitful. It would be expected that the mass-transfer coefficient should increase roughly as the 0.5 to 1.0 power of Reynolds number; however, the range of velocities is too small to clearly show this effect. The most clearly defined correlation seems to be an increase in the mass-transfer coefficient with an increase in the mass of hydrogen deposited (as $\mathrm{NaH}$ ). This relationship is shown in Fig. 7 where the calculated mass-transfer coefficients are plotted as a function of the quantity of hydrogen deposited in the ACT. The calculated mass-transfer coefficient increases by a factor of $\sim 4$ when $\sim 1200 \mathrm{mg} / \mathrm{m}^{2}$ of hydrogen has been deposited. 
Table 2. Summary of Results of Model Calculations

\begin{tabular}{|c|c|c|c|c|c|c|c|c|c|c|}
\hline $\begin{array}{l}\text { Act } \\
\text { No. }\end{array}$ & $\begin{array}{l}\text { Run } \\
\text { Time, ks }\end{array}$ & $\mathrm{Na}$ & $\begin{array}{l}\text { Velocity, } \\
\mathrm{m} / \mathrm{s}\end{array}$ & $\begin{array}{l}\text { Geometric } \\
\text { Area, } \mathrm{m}^{2} / \mathrm{m}\end{array}$ & $\begin{array}{c}\text { Mesh } \\
\text { Densit.y, } \\
\mathrm{kg} / \mathrm{m}^{3}\end{array}$ & $\varepsilon^{a}$ & $\begin{array}{l}\text { Mass Trans. } \\
\text { Coeff } \\
\mathrm{m} / \mathrm{s} \times 10^{-5}\end{array}$ & $\begin{array}{l}\text { Mass of } \\
\mathrm{H}, \mathrm{mg}\end{array}$ & $\begin{array}{l}\mathrm{H} \text { Distr. } \\
\mathrm{mg} / \mathrm{m}^{2}\end{array}$ & $\begin{array}{c}\text { Area } \\
\text { factor } \\
\text { (f) }\end{array}$ \\
\hline 3 & 40.7 & . & .038 & 0.84 & 473 & 0.80 & 7.67 & 41.02 & 79.0 & 1.28 \\
\hline 4 & 112 & & .038 & $0.44^{\circ}$ & 226 & 0.55 & 26.1 & 55.64 & 1170 & 4.35 \\
\hline $5 a$ & 45.0 & $\cdot$ & .019 & 0.43 & 223 & 0.61 & 6.96 & 16.55 & 142 & 1.16 \\
\hline $5 b$ & 55.8 & & & & & 0.72 & 8.07 & 22.25 & 140 & 1.34 \\
\hline $5 c$ & 189 & & & & $\therefore$ & 0.81 & 10.7 & 117.80 & $5: 10$ & 1.78 \\
\hline $6 a$ & 21.6 & & .038 & 0.78 & 434 & 0.61 & 4.52 & 19.40 & 49.4 & 0.75 \\
\hline $6 \mathrm{~b}$ & .79 .2 & & & & & 0.67 & 7.42 & 71.79 & 246 & 1.24 \\
\hline $6 c$ & 193 & & & & - & 0.77 & 13.2 & 177.49 & 737 & 2.20 \\
\hline $7 a$ & 14.4 & . & .038 & .070 & 0 & 0.14 & 7.72 & 1.66 & 68.8 & 1.29 \\
\hline $7 b$ & $41 . .4$ & - & & & . & 0.06 & 3.00 & 3.53 & 117 & -- \\
\hline $7 c$ & 81.9 & & & & & 0.04 & 1.65 & 5.17 & 150 & -- \\
\hline $7 d$ & 144 & & & & & 0.21 & 11.9 & 17.36 & 646 & 1.98 \\
\hline
\end{tabular}

${ }_{\varepsilon}^{a}=$ trapping efficiency. 


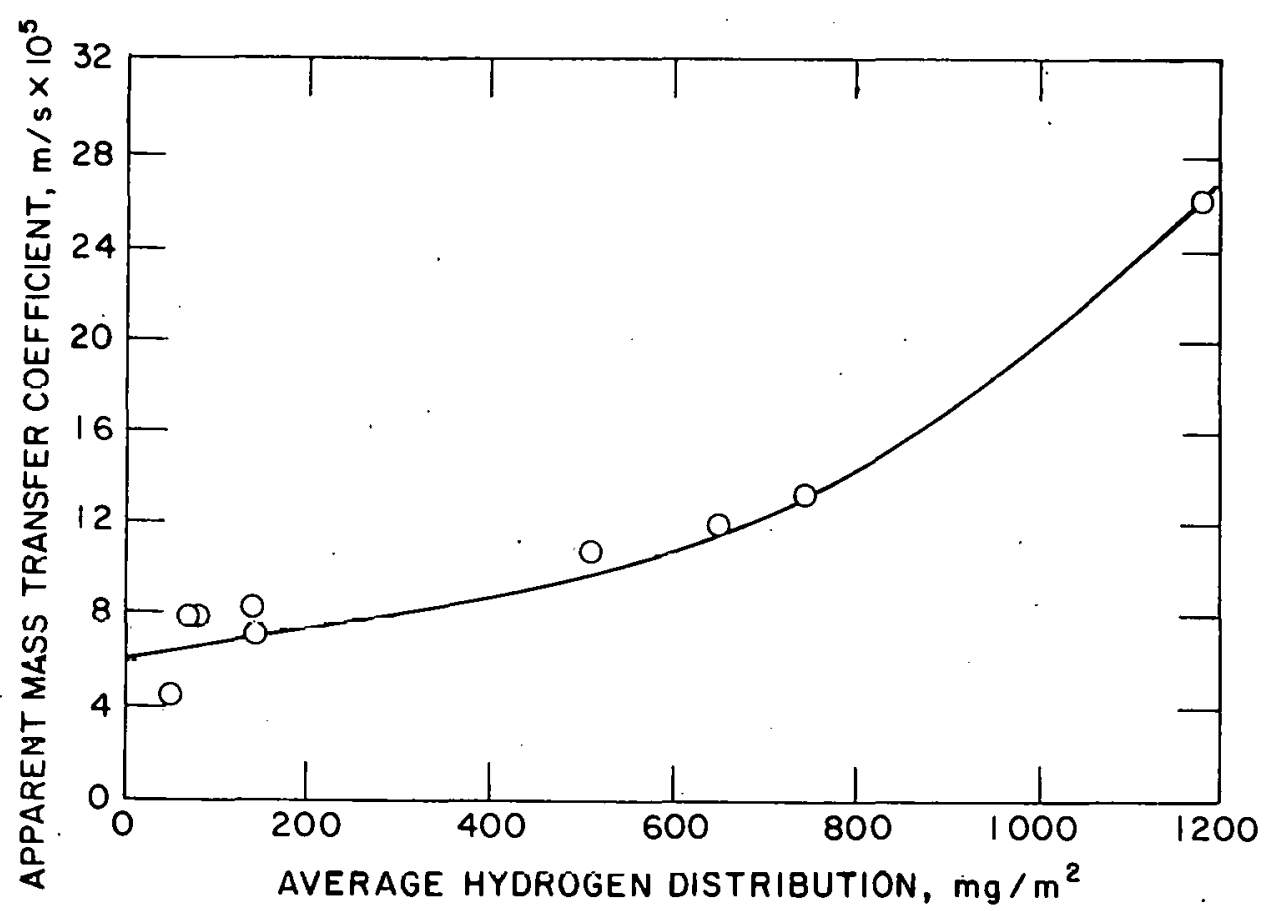

Fig. 7. Effect of Quantity of $\mathrm{NaH}$ Deposited in the ACT on the Mass-Transfer Coefficient

This apparent increase in the mass-transfer coefficient is probably a result of the method of calculation used by the ACTMODEL rather than a true chemical effect. As discussed above, an implicit assumption of the ACTMODEL is that the precipitation surface area remains constant regardless of how much hydride has been deposited. However, the precipitation surface area would be expected to increase as the surface is roughened by NaH crystal deposits. This increase in surface area may be expressed as a modification of Eq. 1:

$$
\frac{\mathrm{dm}}{\mathrm{dt}}=\mathrm{kfA}(\mathrm{C}-\mathrm{Ce})
$$

where the dimensionless area factor, $f$, is a function of the quantity. of $\mathrm{NaH}$ deposited per unit area.

The ACTMODEL, as now written, calculates the quantity, $\mathrm{kf}$, which is called the "mass transfer coefficient". The area factor, $f$, should be unity at the $\mathrm{y}$ intercept of $\mathrm{Fig} .7, i . e$, , when no $\mathrm{NaH}$ has been deposited, the available precipitation surface area is equal to the geometric surface of the stainless steel and $f A=A$. The "mass transfer coefficients", kf, calculated by the ACTMODEL may then be divided by the $y$ intercept $\left(6 \times 10^{-5}\right.$ $\mathrm{m} / \mathrm{s}$ from Fig. 7) to obtain the area factor, $f$, as a function of the quantity of $\mathrm{NaH}$ deposited. Figure 8 is a plot of the area factors obtained in this manner. The line through the data points is expressed by

$$
\log \mathrm{f}=5.18 \times 10^{-4} \mathrm{M}
$$

where $M$ is the mass of hydrogen deposited per unit area, $\mathrm{mg} / \mathrm{m}^{2}$. 


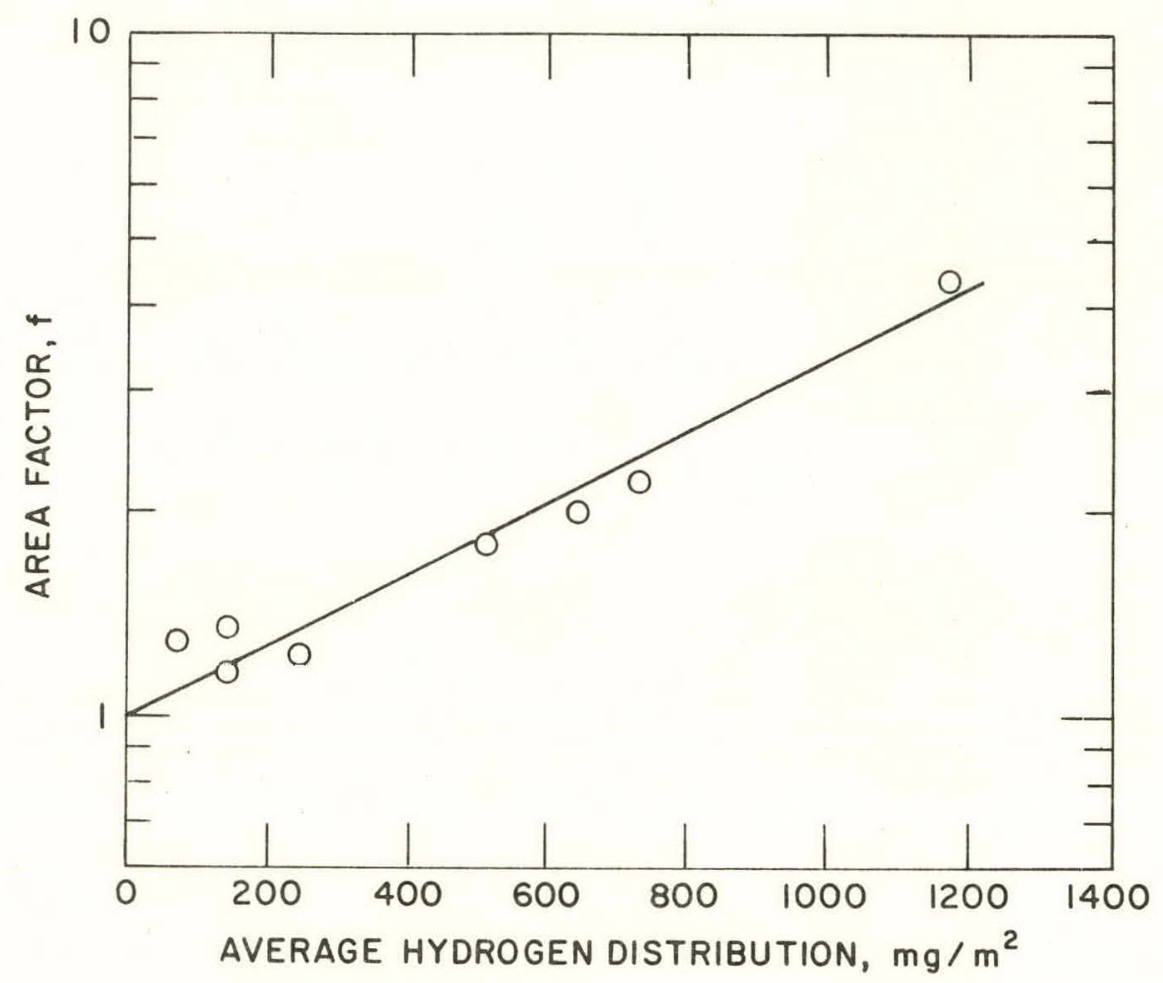

Fig. 8. Effect of NaH Deposition on the Surface Area Available for Precipitation

An increase in effective surface area by a factor of four, as observed in these experiments, can be achieved in many ways. For example, if the $\mathrm{NaH}$ deposits as small cubic crystals, the factor-of-four increase in surface area would occur if $\sim 10^{9}$ crystals of $\sim 25-\mu \mathrm{m}$ size precipitated per square meter of surface. It is more likely, however, that fewer crystals nucleated and that the growth was more needle-like or dendritic, as is the nature of NaH crystals. This open structure could easily achieve a fourfold increase over the bare stainless steel area.

Many of the ACT's were examined after the tests by neutron radiography. This technique was used because it has the capability to reveal NaH deposits in a stainless steel structure. Thermal neutrons are absorbed by the hydrogen, and the $\mathrm{NaH}$ deposits show up as light areas on the film. Figure 9 is a print of the neutron radiograph from packless ACT number 7. The NaH deposits appear dark in this figure because it was contact-printed from the radiograph film.

The NaH deposited in the region of the tee has the appearance of an open, dendritic structure as suggested by the ACTMODEL results. Also, the largest quantity of $\mathrm{NaH}$ deposit seems to be in the tube downstream from the tee. This appearance was deceptive in that the post-test analyses using the $\mathrm{OH}$ analyzer showed a fairly smooth hydrogen distribution as shown in Fig. 10. The analytical results seem to fit the ACTMODEL simulation very well and no exceptionally large $\mathrm{NaH}$ deposits were detected in the region of the tee. Although it is well recognized that locally turbulent zones can cause localized excessive deposition of impurities, the analyses, in this case, failed to show excessive amounts of hydrogen in the tee region. Another significant 


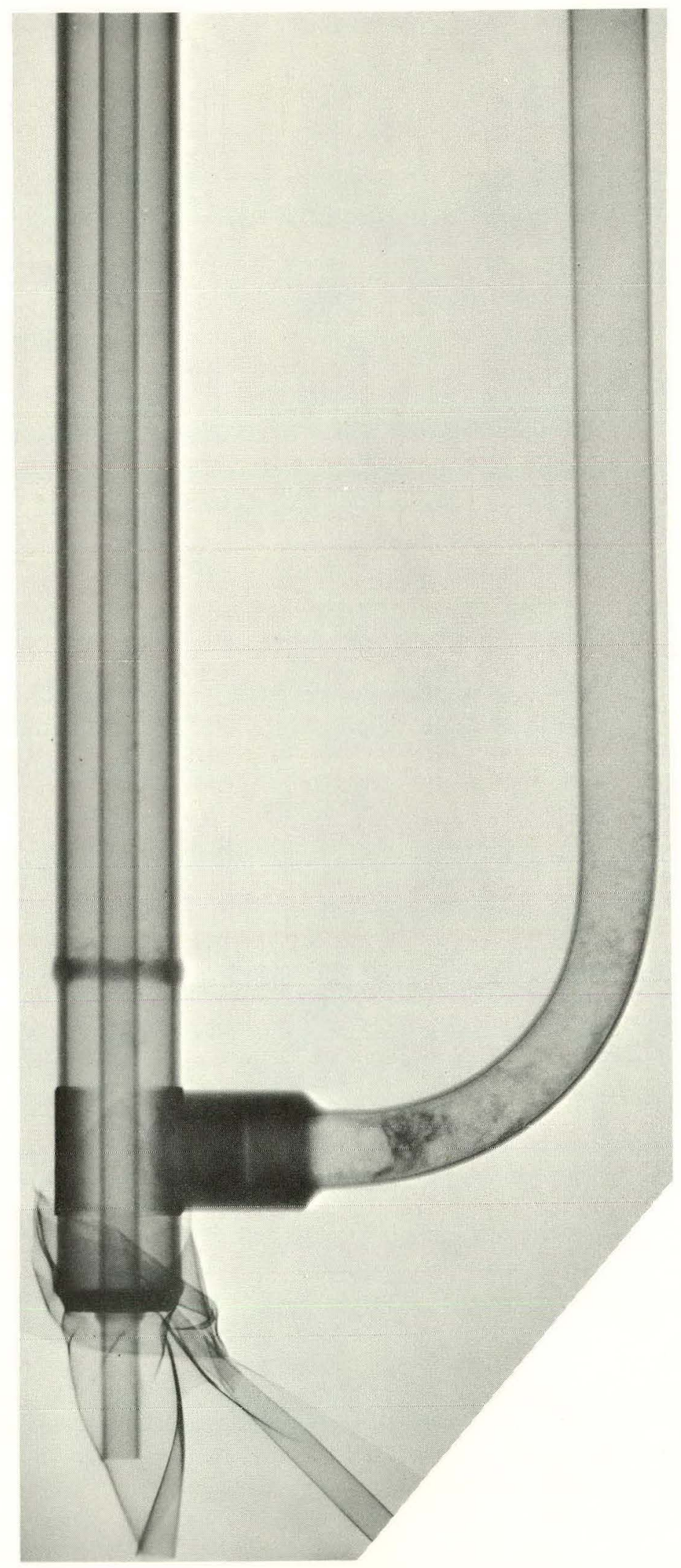

Fig. 9. Contact Print of Post Test Neutron Radiograph of Packless ACT Number 7 


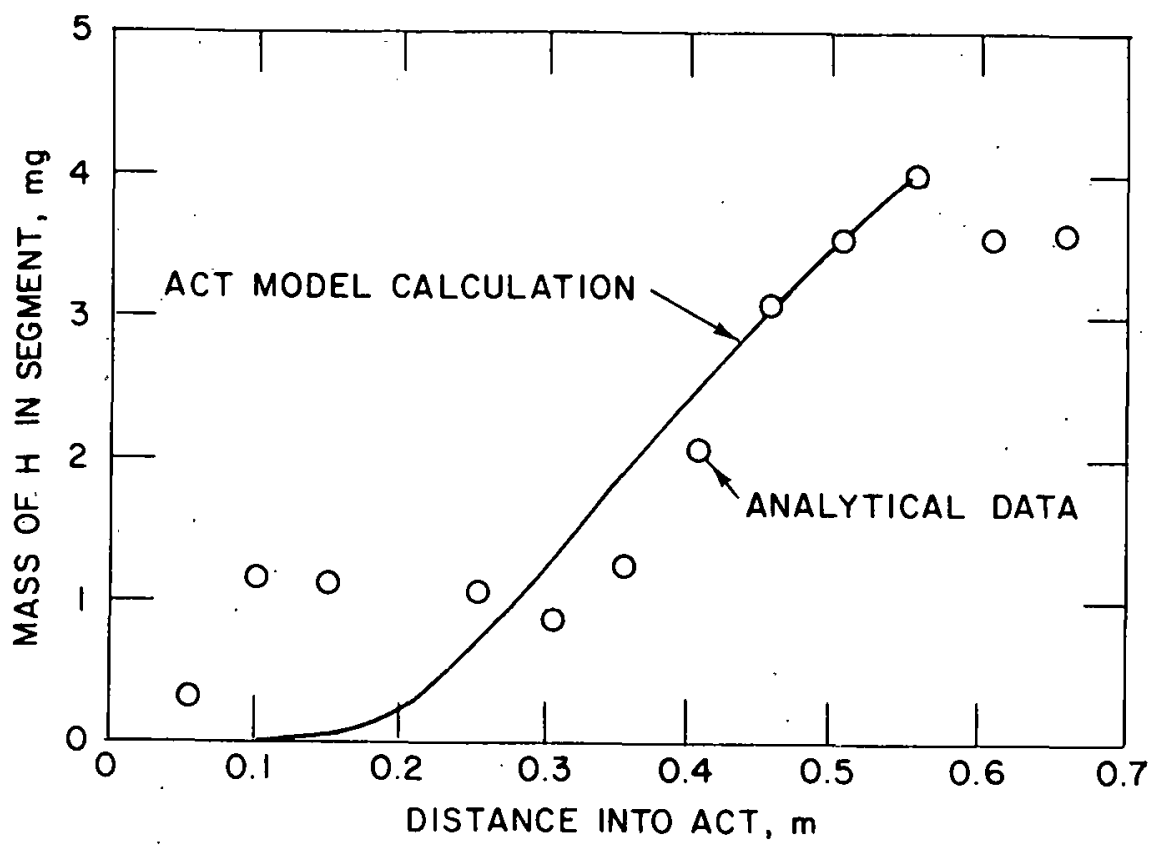

Fig. 10. Hydrogen Distribution in ACT Number 7 as Determined by OHA Analyses

result of this experiment is that no significant nucleation problem seems to exist in the $\mathrm{Na}-\mathrm{NaH}$ system. The $\mathrm{NaH}$ deposition began in the same location predicted by the model, i.e., at the point of saturation of the solution. The presence of hydrogen in the inlet $300 \mathrm{~mm}$ of the ACT may indicate the, presence of some hydrogen-bearing species that precipitates at a higher temperature than the NaH. Although a similar pattern occurred in most of the ACT experiments, these deposits are only of limited interest because the quantity of hydrogen involved is very small.

Figure 11 shows the hydrogen distribution obtained in ACT number 4 and the ACTMODEL simulation. The temperature distribution was such that only the cold end of the ACT was effective in precipitating NaH. Again, the ACTMODEL code accurately predicts the observed hydrogen distribution within the analytical and experimental limitations of the system.

These tests have shown that the ACTMODEL simulation accurately calculates $\mathrm{NaH}$ distributions in this simple.ACT geometry. Although the model cannot, at this stage in its development, handle the complex geometry of a full-scale cold trap, it has shown some general procedures that may be helpful in increasing cold-trap capacity. Critical considerations in maximizing capacity ceem to be controlling the temperature within the the trap and the very careful control of the inlet temperature relative to the saturation temperature. For example, a steep temperature gradient at any location in the trap will cause heavy, localized precipitation and premature plugging in that region before the rest of the mesh is fully utilized. Calculations with ACTMODEL using hypothetical sodium-system parameters have shown that a relatively uniform $\mathrm{NaH}$ mass distribution can be achieved by changing the cold-trap temperature profile during operation. This change in profile could be achieved in practice by dividing a NaK coolant jacket into four (or more) indepently cooled sections to allow greater flexibility in controlling the temperature profile. 


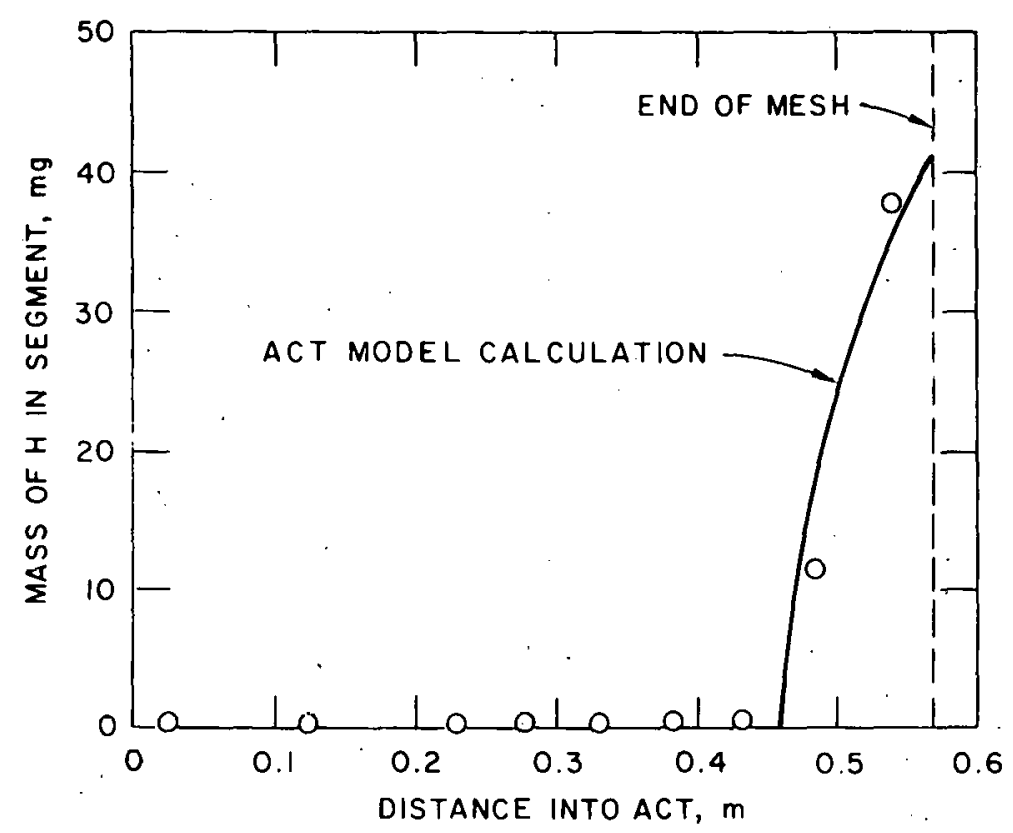

Fig. 11. "Hydrogen Distribution in ACT Number 4 as Determined by OHA Analyses

Increased capacity could also be achieved by grading the mesh packing density to place the most open structure in the region of expected maximum precipitation and the more dense packing in reginns of oxpocted minimuiii precipitation. Controlled mesh packing density and temperature profile should result in maximum utilization of the cold-trap volume.

\section{CONCLUSIONS AND FUTURE WORK}

A series of experiments to determine the nature of $\mathrm{NaH}$ precipitation in cold traps by a combination of computer modeling, experimental studies, and analytical techniques has been completed. This work led to the following conclusions :

1) Significant supersaturation does not appear to occur before nucleation begins when solid surfaces are available for nucleation sites, $i . e$. , précipitation occurs on solid surfaces at all locations cooler than the saturation temperature.

2) Although, in general, the rate of precipitation is expressed adequately by $\mathrm{dm} / \mathrm{dt}=\mathrm{kA}(\mathrm{C}-\mathrm{Ce})$, as $\mathrm{NaH}$ precipitation proceeds, the surface area increases significantly. A fourfold increase in area was observed in these tests.

3) The ACTMODEL code provides excellent simulation of the ACT experiments in terms of predicting the location and quantity of $\mathrm{NaH}$ deposits. The code is also very useful in providing calculations of mass-transfer coefficients and insights into surface area changes during cold-trapping experiments. 
4) A mass-transfer coefficient of approximately $6 \times 10^{-5} \mathrm{~m} / \mathrm{s}$ was observed over the range of these experiments. This compares favorably with values of $4 \times 10^{-5}$ to $1 \times 10^{-4} \mathrm{~m} / \mathrm{s}$ estimated by Hebditch ${ }^{14}$ for a similar system.

5) The 0-H Analyzer (OHA) method has been shown to perform very well in analyzing for hydrogen in sodium samples when sufficient time is allowed for hydrogen diffusion. Complete (100\%) recovery of $\mathrm{Na}_{2} \mathrm{O}$, was observed in all tests containing oxygen.

6) Although neutron radiography can provide valuable information on hydrogen distribution in cold traps, the technique can be deceptive in terms of estimating relative amounts of hydrogen present in different geometric locations.

7) The ACTMODEL has proven to be very helpful in suggesting methods for increasing cold-trap capacity, such as control1ing packing density and temperature profiles.

The ACTMODEL code has been very useful in studying precipitation of NaH in a one-dimensional cold trap; however, it must now be developed further to incorporate radial temperature gradients, radial variations in flow, and radial variations in cold-trap geometry.

Work now in progress at Hanford Engineering Development Laboratory (HEDL) 15 is concerned with determining the flow patterns and temperature profiles expected in full-scale, mesh-packed cold-trap geometries. The HEDL work will be very helpful in completing development of a two-dimensional calculation model for impurity precipitation in cold traps. Future work in cold-trap model development will be directed toward development of this two-dimensional calculational model. Furthermore, the behavior of oxygen in cold-trap precipitation will be studied in a manner similar to the present study with hydrogen. An attempt will be made to observe interactions between the hydrogen and oxygen either in solution or during precipitation in these tests. When these studies are completed and the two-dimensional calculational model is developed, parametric studies"can be done to improv̈e cold-trap designs.

\section{REFERENCES}

1. J. M. McKee and L. E. Poh1, Use of In-Sodium Hydrogen Detectors during Steam Generator Tests in the SCTI, ANS, CONF-740401-P1, 162, (Apri1 1974).

2. P. Roy and D. N. Rogers, Hydrogen Burden from the Stecm Side Corrosion in Sodium-Heated Stecm Generators, Nucl Technol. 39, 213, (July 1978).

3. R. Cygan, HNPF Cold Trop Evaluation, AEC Report NAA-SR-4382, (December 1959).

4. J. Herb, Excomination of the Enrico Fermi Sodium Cold Trap, AEC Report WCAP-4321, (November 1965). 
5. G. Billuris, Experimental Investigation of the Removal of Sodium Oxide from Liquid Sodium, AEC Report GEAP-3328, (January 1960).

6. D. J. Hebditch and B. J. Gliddon, Impurity Crystallization in Liquid Sodium System, ANL Int. Conf. on Liquid Metal Technology in Energy Production, CONF-760503-P2, 643, (May 1976).

7. J. W. Mullin, Crystallization, Butterworths, London (1961).

8. C. C. McPheeters, Mass Transfer of Oxygen in Sodizm Cold Traps, AEC Report LA-3936, (June 1968).

9. B. R. Grundy, Experimental Characterization of Sodium Cold Traps and Modelling of Their. Behavior, ANT Int. Conf. on Liquid Metal Technology in Energy Production, CONF-760503-P2, 650, (May 1976).

10. D. J. Hebditch, C. P..Haigh, and B. J. Gliddon, Sodium Purity Control in CER's--Mechanisms and Rates of Crystal Nucleation and Growth, Centra1 Electricity Generating Board Report R/M/N775, (November 1974).

11. D. R. Vissers, J. T. Holmes, L. G. Bartholme, and P. A. Nelison, A Hydrogen-Activity Meter for Liquid Sodium and its Application to Hydrogen Solubility Measurements, Nuc1. Techno1. 21, 235. (March 1974).

12. E.: Kreyszig, Advanced Engineering Mathematics, John Wiley and Sons, Inc., New York, 1967.

13. R. A. Strehlow and H. C. Savage, The Permeation of Hydrogen Isotopes Through Structural Metals at Low Pressures and Through Metals with oxide Film Barpiers, Nuc1. Technol. 22, 127. (April 1974).

14. D. J. Hebditch, Central Electricity Generating Board, Marchwood Engineering Laboratories, UK, personal communication (January 1979).

15. G. R. Bloom, Hanford Engineering Development Laboratory, Richland, Washington, personal communication (November 1979). 
Distribution for ANL-79-101

Interna :

R. Avery

L. Burris

D. W. Cissel

S. A. Davis

P. R. Fields

B. R. T. Frost

E. V. Krivanec

R. J. Teunis

C. E. Till

R. S. Zeno
F. A. Cafasso (3)

P. T. Cunningham

J. E. Harmon

L. J. Jardine

V. J. Kremesec

V. A. Maroni

J. M. Mc Kee

C. C. McPheeters (10)

B. Misra
W. H. 01 son

M. M. Osterhout

D. J Raue

T. A. Renner

S. B. Skladzien

R. D. Wolson

A. B. Krisciunas ANL Contract File

ANL Libraries (5)

TIS Files (6)

External:

DOE-TIC, for distribution per UC-79a (183)

Manager, Chicago Operations and Regional Office, DOE Chief, Office of Patent Counse1, DOE-CORO

Director, Technology Management, DOE-CORO

Director, DOE-RRT (2)

President, Argonne Universities Association

Chemical Engineering Division Review Committee:

C. B. Alcock, U. Toronto

R. C. Axtmann, Princeton U.

J. T. Banchero, U. Notre Dame

T. Cole, Ford Motor Co.

P. W. Gilles, U. Kansas

R. I. Newman, Warren, N. J .

H. Perry, Resources for the Future, Washington

G. M. Rosenblatt, Pennsylvania State U.

W. L. Worrell, U. Pennsylvania 